(RA), to identify those who may benefit from preventive interventions. However, it is important to understand the views of those who may be candidates for such predictive tests, to inform the development of effective approaches. First degree relatives (FDRs) of patients with RA are at an increased risk of developing RA. RA patients can provide access to FDRs. Qualitative investigations have explored the views of these groups about predictive testing for $R A^{1,2}$, but quantitative approaches are needed to develop a robust understanding.

Objectives: To identify predictors of interest in predictive testing for FDRs and patients, and to assess the likelihood of patients communicating information about RA risk to their FDRs.

Methods: Surveys were completed by 482 RA patients and 397 of their FDRs. Patients were invited to complete the survey and to provide another to their relatives. Spearman's Rank Correlations were used to assess relationships between interest in predictive testing/ likelihood of risk communication and potential predictor variables.

Results: FDRs had a median age of 41 years, $64 \%$ were female. $57 \%$ were definitely interested and $36 \%$ were probably interested in taking a predictive test for RA. Several predictors were found to be associated with interest (table 1).

Table 1. Spearman's correlations for relatives' and patients' interest in predictive testing. After applying a Bonferonni adjustment, $p$ values were taken as statistically significant at $p \leq 0.003$.

\begin{tabular}{|c|c|c|c|c|}
\hline \multirow[b]{2}{*}{ Predictors of interest in predictive testing } & \multicolumn{2}{|c|}{ FDRs } & \multicolumn{2}{|c|}{ Patients } \\
\hline & rs & $\mathrm{P}$ & rs & $\mathrm{P}$ \\
\hline Brief Illness Perception Questionnaire & 0.11 & 0.03 & 0.09 & 0.05 \\
\hline Consequences & $0.16^{*}$ & $0.002^{*}$ & 0.10 & 0.03 \\
\hline Timeline & 0.09 & 0.07 & -0.05 & 0.28 \\
\hline Personal control & -0.03 & 0.59 & -0.02 & 0.68 \\
\hline Treatment control & -0.02 & 0.76 & 0.02 & 0.74 \\
\hline Identity & 0.09 & 0.09 & 0.12 & 0.01 \\
\hline Concern & $0.21^{*}$ & $<0.001^{\star}$ & $0.16^{\star}$ & $<0.001^{*}$ \\
\hline Coherence & 0.11 & 0.03 & 0.007 & 0.88 \\
\hline Emotional & 0.12 & 0.02 & 0.11 & 0.02 \\
\hline Information Seeking & $0.35^{*}$ & $<0.001^{*}$ & $0.22^{*}$ & $<0.001^{*}$ \\
\hline Decision making & -0.05 & 0.33 & 0.07 & 0.13 \\
\hline Health literacy & 0.03 & 0.52 & 0.02 & 0.62 \\
\hline Health numeracy & -0.06 & 0.23 & -0.02 & 0.72 \\
\hline Brief Avoidance Coping Questionnaire & 0.12 & 0.02 & -0.01 & 0.76 \\
\hline Optimism & 0.06 & 0.26 & -0.07 & 0.12 \\
\hline Health anxiety & $0.16^{*}$ & $0.001^{*}$ & - & - \\
\hline Perceived risk & $0.37^{*}$ & $<0.001^{*}$ & - & - \\
\hline Rheumatoid Arthritis Impact of Disease & - & - & 0.05 & 0.31 \\
\hline
\end{tabular}

- not applicable

Patients had a median age of 65 years, $71 \%$ were female. $47 \%$ were definitely interested and $30 \%$ were probably interested in their children taking a predictive test. Several predictors were found to be associated with interest (table 1). On a Likert scale from extremely unlikely $(0)$ to extremely likely (4), most patients indicated that they were likely to communicate RA risk information to their children (median score=3).

Conclusion: Interest in predictive testing for RA was high amongst FDRs, and factors including information seeking preference, RA risk perception, concern about RA, perceived consequences of RA and health anxiety were significantly associated with interest. Patients were also willing to communicate information about RA risk to their children. These findings increase understanding of perceptual variation in those at risk of RA, and will inform the development of information to support decision making in individuals considering predictive tests and preventive interventions. We are currently extending this preliminary analysis by building multivariate models incorporating a range of attitudes about predictive testing, assessing predictors of patients' likelihood of communicating to their FDRs about risk, and the relationship between patients' and FDRs' responses.

References:

[1] Stack RJ et al. BMJ open. 2016; 6(6):e010555.

[2] Falahee M et al. Arthritis care \& research. 2017; 69(10):1558-65.

Acknowledgments: This work was supported by Versus Arthritis; Grant reference: 21560

Disclosure of Interests: Imogen Wells: None declared, Gwenda Simons: None declared, Rebecca Stack: None declared, Christian Mallen Grant/research support from: My department has received financial grants from BMS for a cardiology trial., Peter Nightingale: None declared, Karim Raza Grant/research support from: KR has received research funding from AbbVie and Pfizer, Consultant of: KR has received honoraria and/or consultancy fees from AbbVie, Sanofi, Lilly, Bristol-Myers Squibb, UCB, Pfizer, Janssen and Roche Chugai, Speakers bureau: KR has received honoraria and/or consultancy fees from AbbVie, Sanofi, Lilly, Bristol-Myers Squibb, UCB, Pfizer, Janssen and Roche Chugai, M. Falahee: None declared

DOI: 10.1136/annrheumdis-2020-eular.2175

\section{OP0265-HPR FACTORS ASSOCIATED WITH MEETING WORK DEMANDS FOR INDIVIDUALS WITH RHEUMATIC DISEASES}

D. Connolly ${ }^{1}$, C. Fitzpatrick ${ }^{1}$, L. O'toole ${ }^{1}$, F. O'shea ${ }^{2}$, M. Doran ${ }^{2} .{ }^{1}$ Trinity College Dublin, Occupational Therapy, Dublin, Ireland; ' $S t$. James' Hospital, Rheumatology, Dublin, Ireland

Background: Almost $65 \%$ of individuals with rheumatic diseases have severe fatigue with the majority of these reporting difficulties in work leading to absenteeism and early retirement. However, there is a lack of research investigating how different types of fatigue impact on work ability.

Objectives: To identify the prevalence of different types of fatigue and explore the association between different types of fatigue and various demands involved in work Methods: A cross-sectional study was carried out with 234 individuals with rheumatic diseases currently in employment. Study measures examined demographics, different types of fatigue (general, physical reduced activity, reduced motivation and mental), ability to meet work demands, disease activity and quality of life.

Results: The majority of participants were female (70\%), had rheumatoid arthritis $(42.7 \%)$, were between $41-50$ years $(30.3 \%)$ and worked full-time $(70 \%)$. One hundred and twenty-eight participants (55\%) had severe fatigue. Physical fatigue was the most prevalent category of fatigue (Table 1). Participants reported managing $50 \%$ of their work demands with physical demands being the most challenging (Table 1). All types of fatigue were significantly associated with the total WRF score (Table 2). Mental fatigue had the strongest association with the total WRF score $(r=0.53, p<0.001)$. On examining the impact of different types of fatigue on meeting work demands, mental fatigue was the most significant predictor of difficulty meeting work demands $(\beta=1.6, \mathrm{SE}=0.37, p<0.001)$

Table 1. MFI and WRF total and category scores

\begin{tabular}{lcccccc}
\hline $\begin{array}{l}\text { WRF } \\
\mathbf{n}=212\end{array}$ & $\begin{array}{c}\text { Total } \\
\text { mean } \\
\text { (SD) }\end{array}$ & $\begin{array}{c}\text { Work Scheduling } \\
\text { Demands mean } \\
\text { (SD) }\end{array}$ & $\begin{array}{c}\text { Output } \\
\text { demands } \\
\text { mean (SD) }\end{array}$ & $\begin{array}{c}\text { Physical } \\
\text { Demands } \\
\text { mean (SD) }\end{array}$ & $\begin{array}{c}\text { Mental } \\
\text { Demands } \\
\text { mean (SD) }\end{array}$ & $\begin{array}{c}\text { Social } \\
\text { Demands } \\
\text { mean (SD) }\end{array}$ \\
\hline $50.3 \%(19.0)$ & $44.6 \%(25.8)$ & $52.9 \%(22.1)$ & $43.3 \%(27.9)$ & $53.4 \%(22.5)$ & $62.4 \%(17.7)$ \\
\hline $\begin{array}{l}\text { MFI } \\
\mathbf{n}=220\end{array}$ & $\begin{array}{c}\text { Total } \\
\text { mean (SD) }\end{array}$ & $\begin{array}{c}\text { Physical fatigue } \\
\text { mean (SD) }\end{array}$ & $\begin{array}{c}\text { Reduced } \\
\text { activity } \\
\text { mean (SD) }\end{array}$ & $\begin{array}{c}\text { Reduced } \\
\text { motivation } \\
\text { mean (SD) }\end{array}$ & $\begin{array}{c}\text { Mental fatigue } \\
\text { mean (SD) }\end{array}$ & \\
\hline & $13.4(2.8)$ & $12.5(4.3)$ & $10.1(4.2)$ & $10.2(3.5)$ & $10.3(4.2)$ & \\
\hline
\end{tabular}

Table 2. Correlations for WRF and MFI fatigue categories

\begin{tabular}{lcc}
\hline MFI Category & Correlations with total WRF & p-values \\
\hline General fatigue & .53 & $<0.001$ \\
Mental fatigue & .57 & $<0.001$ \\
Physical fatigue & .48 & $<0.001$ \\
Reduced motivation & .48 & $<0.001$ \\
Reduced activity levels & .41 & $<0.001$ \\
\hline
\end{tabular}

Conclusion: Fatigue interferes with many aspects of work performance. However, this study identifies that mental fatigue is the greatest predictor of difficulty in managing work. Self-management interventions focusing on mental fatigue and work ability are required for individuals with rheumatic diseases to manage the demands of their work.

Disclosure of Interests: None declared

DOI: 10.1136/annrheumdis-2020-eular.5550

\section{OP0266-HPR WORK PRODUCTIVITY IN PATIENTS WITH AXIAL AND PERIPHERAL SPONDYLOARTHRITIS}

C. Airoldi ${ }^{1}$, P. Girard Bosch ${ }^{2}$, M. Benegas ${ }^{3}$, V. Duarte ${ }^{4}$, V. Cosentino ${ }^{5}$,

F. Sommerfleck ${ }^{3}$, J. Marin ${ }^{6}$, J. M. Bande ${ }^{7}$, J. Gamba ${ }^{8}$, R. Águila Maldonado ${ }^{9}$, E. Velozo ${ }^{10}$, M. Oliver ${ }^{11}$, R. Nieto ${ }^{1}$, P. Gonzalez ${ }^{12}$, D. Vila ${ }^{13}$, E. Kerzberg ${ }^{5}$,

M. Cosatti ${ }^{14}$, J. Tapia $^{5}$, P. Giorgis ${ }^{15}$, L. L. Macias Oviedo ${ }^{15}$, E. Schneeberger ${ }^{15}$

S. Scarafia ${ }^{16}$, V. Martire ${ }^{2} .{ }^{1}$ Hospital Provincial de Rosario, Rosario,

Argentina; ${ }^{2}$ Instituto Médico Platense, La Plata, Argentina; ${ }^{3}$ Mendez, CABA, Argentina; ${ }^{4}$ Clínica Monte Grande, Buenos Aires, Argentina; ${ }^{5}$ Hospital Ramos Mejia, CABA, Argentina; ${ }^{6}$ Hospital Italiano de Buenos Aires, CABA, Argentina; ${ }^{7}$ Hospital Tornú, CABA, Argentina: ${ }^{8}$ Hospital Posadas, Buenos Aires, Argentina; ${ }^{9}$ Hospital San Martin de La Plata, La Plata, Argentina; ${ }^{10}$ Sanatorio Adventista del Plata, Entre Rios, Argentina; ${ }^{11}$ Hospital Privado de Comunidad de Mar del Plata, Mar del Plata, Argentina; ${ }^{12}$ Clinica DIM, Buenos Aires, Argentina; ${ }^{13}$ Centro Médico Ginecológico de Zárate, Buenos 
Aires, Argentina; ${ }^{14}$ CEMIC, CABA, Argentina; ${ }^{15}$ Instituto de Rehabilitación Psicofísica, CABA, Argentina; ${ }^{16}$ Hospital Municipal San Cayetano, Buenos Aires, Argentina

Background: Work disability is an important outcome in the treatment of Spondyloarthritis (SpA) since this disease affects people in the most productive stage of life.

Objectives: The aim of this study is to investigate the working status and the factors associated with work productivity loss (WPL) in patients with axial (axSpA) and peripheral SpA (pSpA).

Methods: Patients with SpA according to ASAS criteria were included consecutively in this multicentric cross-sectional study. Evaluation of activity through a visual analogue scale (0-100), enthesitis (LEI), functional capacity (HAQ and BASFI), disease activity (DAS28 and BASDAI), health status (ASAS Health Index) and quality of life (ASQoL) were calculated. The Ankylosing Spondylitis Disease Activity Score (ASDAS) was recorded. The Work Productivity and Activity Impairment Spondyloarthritis (WPAI SpA) questionnaire was used to assess work productivity.

Spearman's correlation coefficient $(\rho)$ was used to assess the correlation with the percentage of WPL.

Results: 274 patients with SpA were recruited, 129 (47.1\%) with axSpA and 145 (52.9\%) with pSpA. $56.6 \%$ were women and $33.2 \%$ stopped working due to the underlying disease.

Among axSpA patients, $70 \%$ were radiographic and $30 \%$ non radiographic, mean age 45.5 (SD14) yrs, median disease duration 72 (IQR 36-144) months and diagnosis delay 20 (IQR 11-70) months. 45.7\% were employed, median hours worked in the last week was 40 (IQR 25-45), median scores for absenteeism was $0 \%$ (IQR 0-2), presenteeism 30\% (IQR 5-40), WPL 30\% (IQR 10-52.5) and activity impairment 30\% (IQR 10-50). A positive correlation was found between WPL and the following variables: $\operatorname{HAQ}(\rho: 0.40, p<0.001)$, BASDAI $(\rho: 0.48, p<0.001)$, ASDAS ( $\rho: 0.46, p<0.001)$, BASFI $(\rho: 0.59, p<0.001)$, ASQoL ( $\rho: 0.60, p<0.0001)$, LEI ( $\rho: 0.31, p: 0.02)$ and ASAS health index $(\rho: 0.54, p<0.001)$.

Among pSpA patients, mean age was 52.3 (SD13) yrs, median disease duration 60 (IQR 14-120) months and diagnosis delay 12 (IQR 3-24) months. 46.9\% were employed, median hrs worked in the last week was 30 (IQR 14-40), absenteeism $0 \%$ (IQR 0-7), presenteeism 30\% (IQR 2.5-58), WPL 30\% (IQR 5-52) and activity impairment 20\% (IQR 0-40). A positive correlation was found between WPL and: HAQ ( $\rho: 0.49, p<0.001)$, ASDAS ( $\rho: 0.58, p<0.001)$, ASQoL $(\rho: 0.57, p<0.0001)$, DAS28 ( $\rho: 0.50, p<0.001)$, LEI $(\rho: 0.36, p: 0.04)$ and ASAS health index $(\rho: 0.52$, $p<0.001)$. No statistically significant differences were found in absenteeism, presenteeism, WPL and activity impairment between axSpA and pSpA.

Conclusion: Our study showed that WPL in this national cohort was $30 \%$ in both groups of patients and is associated with disease activity, enthesitis, health status, quality of life and functional ability.

Disclosure of Interests: None declared

DOI: 10.1136/annrheumdis-2020-eular.5960

\section{OP0267-HPR "I NEVER THOUGHT EXERCISE COULD HELP IMPROVE MY SLEEP”: EXPERIENCES OF PEOPLE WITH RHEUMATOID ARTHRITIS ON THE IMPACT OF EXERCISE ON SLEEP}

S. Mckenna ${ }^{1,2}$, L. Larkin ${ }^{1,2}$, A. Donnelly, $y^{2,3}$ A. Fraser ${ }^{4,5}$, B. A. Esbensen ${ }^{6,7}$, N. Kennedy ${ }^{1,2}$. ${ }^{1}$ University of Limerick, School of Allied Health, Limerick, Ireland; ${ }^{2}$ University of Limerick, Health Research Institute, Castletroy, Ireland; ${ }^{3}$ University of Limerick, Department of Physical Education and Sport Sciences, Limerick, Ireland; ${ }^{4}$ University Hospitals Limerick, Department of Rheumatology, Limerick, Ireland; ${ }^{5}$ University of Limerick, Graduate Entry Medical School, Limerick, Ireland; ${ }^{6}$ Rigshospitalet, Center for Rheumatology and Spine Diseases, Copenhagen, Denmark; ${ }^{7}$ University of Copenhagen, Department of Clinical Medicine, Copenhagen, Denmark

Background: OMERACT has identified sleep quality as one of the key outcomes for people with RA [1]. Poor sleep and reduced total sleep time (TST) are common complaints among people with RA. Poor sleep can in turn lead to deterioration in function, reduce activity levels and also impact mental health. Although sleep and mental health outcomes have been identified as important, they are frequently not measured in clinical trials. Involving key stakeholders, like people with RA, is important when designing exercise interventions as it allows consideration of particular issues that may influence future intervention delivery. This study involved people with RA who participated in a pilot RCT group exercise class to improve sleep quality.

Objectives: To explore participants experiences of an exercise intervention in improving sleep quality and TST, to capture their reality.

Methods: A descriptive qualitative study design of face-to-face semi-structured interviews was employed. The interview schedule explored a number of areas: experience of the intervention; outcome measures used; views regarding the intervention; perceptions regarding exercise and sleep and the impact on sleep.
Interviews were transcribed verbatim by a professional transcriber. Inductive thematic analysis was used as an analytical approach. Interview transcripts were read, notes made, and ideas formulated to facilitate coding. The research team searched for patterns, analysed and coded the data, and generated themes and sub-themes. Themes were reviewed by the research team to check if they worked in relation to the coded extracts and the entire data set. The COREQ checklist provided guidance.

Results: Twelve females participated with a mean age of 58 (SD 7.4); mean RA diagnosis of 9.9 (SD 7.4) years; moderate to severe disability (HAQ-DI: 1.5 (SD 0.60). Four main themes were generated: 1) Positive impact of exercise on sleep - "I really didn't think any type of exercise would help me sleep better if I'm honest."; 2) Positive experiences of exercise intervention to improve sleep -"I learnt so much regarding walking that I didn't even think about."; 3) Clear mental health benefits - "If you don't sleep well then it will have a knock-on effect to your mental health"; 4) Achieving empowerment and ownership when exercising - "I feel empowered now and confident that l'm not doing harm to myself". The findings demonstrated that participants were clearly surprised that exercise could improve sleep.

Conclusion: In a variety of inflammatory conditions exercise is recommended as an effective intervention for the treatment of sleeping disorders. Although there is a growing consensus that exercise will benefit sleep, research is severely lacking in those with RA. This study demonstrates that participants were clearly surprised that exercise could improve their sleep. Due to the multifactorial nature of $R A$, engaging in exercise may not only improve sleep quality but also mitigate some of its symptoms.

References:

[1] Kirwan JR, Boonen A, Harrison MJ, Hewlett SE, et al (2011) OMERACT 10 Patient Perspective Virtual Campus: Valuing health; measuring outcomes in rheumatoid arthritis fatigue, RA sleep, arthroplasty, and systemic sclerosis; and clinical significance of changes in health. The Journal of Rheumatology;38:1728-34.

Disclosure of Interests: None declared

DOI: 10.1136/annrheumdis-2020-eular.168

\section{OP0268-HPR RHEUMATIC DISEASE PATIENTS' PREFERENCES IN ADVERSE DRUG REACTION INFORMATION REGARDING BIOLOGICS}

G. Weits ${ }^{1}$, L. Kosse ${ }^{1}$, H. Vonkeman ${ }^{2}$, P. Spuls ${ }^{3}$, B. Van den Bemt ${ }^{4,5}$, S. Tas ${ }^{6}$, F. Hoentjen ${ }^{7}$, M. Nurmohamed ${ }^{8}$, M. Van Doorn ${ }^{9}$, E. Van Puijenbroek ${ }^{1,10}$, N. Jessurun ${ }^{1}{ }^{1}$ Netherlands Pharmacovigilance Centre Lareb, 's-Hertogenbosch, Netherlands; ${ }^{2}$ Rheumatology, Medisch Spectrum Twente, Enschede, Netherlands; ${ }^{3}$ Dermatology, Amsterdam University Medical Centers, Amsterdam, Netherlands; ${ }^{4}$ Sint Maartenskliniek, Nijmegen, Netherlands; ${ }^{5}$ Radboud University Medical Center, Nijmegen, Netherlands; ${ }^{6}$ Rheumatology, Amsterdam University Medical Centers, Amsterdam, Netherlands; ${ }^{7}$ Gastroenterology, Radboud University Medical Center, Nijmegen, Netherlands; ${ }^{8}$ Reade Rheumatology, Amsterdam, Netherlands; ${ }^{9}$ Dermatology, Erasmus Medical Center, Rotterdam, Netherlands; ${ }^{10}$ Groningen Research Institute of Pharmacy, University of Groningen, Groningen, Netherlands

Background: Patient-reported outcomes (PROs) are increasingly used in studies and medical practice to obtain information on patients' perspectives towards their treatment or disease. However, study outcomes are primarily directed at and shared with healthcare professionals, even though the results may also be relevant for patients.

Objectives: The objective of this study was to obtain insight in which results patients with immune-mediated inflammatory diseases (IMIDs), including inflammatory rheumatic disease patients, prefer to receive after participating in the Dutch Biologic Monitor.

Methods: The Dutch Biologic Monitor is a PRO-based prospective cohort event monitoring study focused on adverse drug reactions (ADRs) [1]. A survey was conducted among the participants of the Dutch Biologic Monitor who wanted to be informed about the results. Patients' preferences were identified using twelve statements and rated with five-point Likert-type scales. Averages described the preference per statement. Preference for the results per IMID or altogether was assessed using Mann-Whitney U Test.

Results: Respondents (N=591, response rate $67.6 \%$ ) preferred results per IMID over aggregated results $(p=<0.001)$. Information on whether patients with the same IMID experience ADRs (average 4.5), which biologics are most likely to cause ADRs (4.4) and whether the ADRs subside or disappear (4.4) were regarded as most interesting. Outcomes of patients with other IMIDs (3.5), patient characteristics (3.7) and injection site reactions (3.8) were least interesting. 